\title{
Pro-Drop and Impoverishment
}

Gereon Müller (Universität Leipzig)

October 6, 2005

\section{Introduction}

It is often assumed that some notion of morphological richness plays a central role in the theory of pro-drop: In languages with sufficiently rich verbal $\phi$-feature (person, number, gender) agreement morphology, pronominal arguments can (and, in some contexts, must) remain without phonological realization; in languages without such a rich verbal agreement morphology, pronominal arguments must be overtly realized. Focussing on subject pro-drop here and in what follows, this difference can be illustrated with evidence from Spanish and Italian on the one hand (languages with rich subject agreement morphology), and English and German on the other (languages without rich subject agreement morphology); see (1-ab) vs. (1-cd). Following Chomsky (1982), Rizzi (1986), and Grewendorf (1989), among many others, I assume that the pro-drop phenomenon does not involve post-syntactic deletion (cf. Perlmutter (1971)), but an empty category pro. Such a non-overt pronoun pro is merged in the canonical position for subjects (in Spec of $\mathrm{vP}$ or within the VP, depending on its status as an external or internal argument), and undergoes Agree with $\mathrm{T}$ in the languages under consideration here (which rely on a nominative/accusative system of argument encoding), thereby ensuring nominative case and subject agreement; cf. Chomsky $(1995 ; 2001) .{ }^{1}$

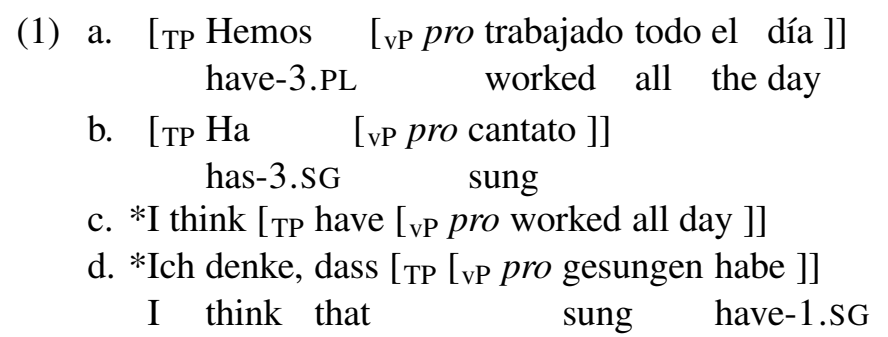

Even though the hypothesis that morphological richness is involved in the licensing of argumental pro seems to be a natural one, and is widely accepted, it has proven extremely difficult to pin down. In fact, it seems that the notion of morphological richness relevant here is left somewhat vague in most of the relevant literature. Jaeggli \& Safir $(1989,29-30)$ assume that pro-drop is possible in languages with morphologically uniform inflectional paradigms, where an inflectional paradigm counts as uniform iff it "has either only underived inflectional forms or only derived inflectional forms": The former option covers pro-drop languages like Spanish and Italian; the latter option covers pro-drop languages like Japanese or Chinese, which lack verbal $\phi$-feature agreement completely; non-pro drop languages like English and French, which have bare-stem inflectional forms in their verbal paradigms, are correctly excluded. As noted by Rohrbacher (1999, ch. 5), this approach ignores the fact that base-stem forms can act as fully distinctive members of morphological paradigms (and are accordingly often analyzed as involving null morphemes in morphology that are accorded the same formal status as

\footnotetext{
${ }^{1}$ See Grimshaw \& Samek-Lodovici (1998) for an elaboration of the information-structural restrictions on overt vs. nonovert realization of subject argument pronouns in pro-drop languages. Non-pro drop languages may exhibit phenomena which at first sight resemble pro-drop constructions; compare, e.g., diary and cookbook contexts in English, or the topic drop phenomenon in German. I will disregard such phenomena throughout this paper. Furthermore, I will not have anything to say about constructions involving meteorological predicates, impersonal passives, subject inversion, and the like, where some languages may need overt expletive or 'quasi-argumental' pronouns, and others do not. It has been argued that these phenomenona may also involve pro (as argued, e.g., by Rizzi (1986) for Italian, Platzack (1987) for Icelandic, and Grewendorf (1989; 1990) for German), but there is also evidence against such a view; see, e.g., Haider (1988), Rohrbacher (1999). I will confine myself to clear cases of argumental pro-drop in what follows, and would like to leave open the question of whether pro can also show up in expletive or quasi-argumental contexts. Finally, I assume here that pro does not have to raise to SpecT in order to satisfy some EPP property, which brings the analysis closer to 'I-subject' approaches as in Borer (1986), Alexiadou \& Anagnostopoulou (1998); however, not much depends on this in the present context.
} 
other, overt inflection markers). Rohrbacher proposes a slightly more elaborate approach according to which a language can have pro-drop if "in at least one number of one tense, the person features [1] and [2] are distinctively marked" (pp. 130, 247). Notwithstanding empirical differences between these approaches, it seems clear that they all do not straightforwardly exclude languages like German or Icelandic (which distinguish 1. and 2. person in paradigms) as pro-drop languages; but both languages lack subject argument pro. Furthermore, these approaches crucially presuppose a concept of inflectional paradigm that corresponds to the traditional notion adopted in reference grammars, but that is incompatible with recent devlopments in theoretical morphology. Here, paradigms are often viewed as epiphenomena, i.e., descriptive generalizations that principles of grammar cannot refer to by definition (e.g., this holds for all of the work carried out within Distributed Morphology; see Halle \& Marantz (1993; 1994), Bobaljik (2002b), among many others); or they are viewed as abstract grammatical objects that bear little resemblance to the traditional reference grammar notion (compare, e.g., the notions of paradigm in Williams (1994), Wunderlich (1996), and Wiese (1999)).

In view of this state of affairs, the main goal of the present paper is to argue for a concept of morphological richness underlying the theory of pro-drop that is based on recent morphological research and correctly derives the cross-linguistic distribution of subject argument pro. The central claim that I want to propose here is that morphological richness should be captured not by looking at and counting distinctive forms of traditional paradigms (which I assume to be mere epiphenomena), but rather by invoking an abstract property of morphological inventories - more specifically, by relying on the concept of impoverishment developed in Distributed Morphology. For concreteness, I would like to suggest that pro cannot be licensed by $\mathrm{T}$ if $\mathrm{T}$ is subject to an impoverishment operation that leads to a neutralization of $\phi$-features.

The argument consists of three steps. In section 2, I look at the morphological system of verb inflection in German. I develop a Distributed Morphology approach that makes crucial use of the classical morphological techniques of decomposition of person features and underspecification of inflection markers with respect to these features. In addition, it employs two mechanisms that only exist in Distributed Morphology: fission and impoverishment. Fission permits a subanalysis of markers. Even more importantly in the present context, impoverishment will be shown to derive systemwide patterns of syncretism (where syncretism is conceived of as systematic homonymy of inflection markers). In section 3, I make a first attempt to derive the absence of pro-drop from the presence of impoverishment, and I discuss the problems that arise with this view under standard conceptions of the morphology/syntax interface, where impoverishment is post-syntactic and pro-licensing is not. To solve this dilemma, a pre-syntactic concept of impoverishment is called for. In section 4, I argue that there is independent evidence for this: Given minimalist assumptions, post-syntactic vocabulary insertion as it is standardly assumed in Distributed Morphology should be replaced by pre-syntactic probe-driven Merge. In line with this, post-syntactic impoverishment should be reformulated as presyntactic impoverishment. In section 5, I present and justify the main claim of this paper, viz., that $\phi$-feature impoverishment blocks the licensing of pro. This approach is then tested against evidence from Icelandic, Modern Irish, and Russian. Section 6 draws a conclusion.

\section{German Verb Inflection}

\subsection{Background Assumptions}

Let me begin by sketching some basic assumptions of Distributed Morphology (see Halle \& Marantz (1993; 1994), Harley \& Noyer (2003)). A core concept is that of late vocabulary insertion: Abstract functional morphemes like $\mathrm{v}$ and $\mathrm{T}$ (cf. Chomsky (1995)) contain fully specified bundles of morphosyntactic features in syntax; however, they do not yet contain phonological material. ${ }^{2}$ The actual

\footnotetext{
${ }^{2}$ It is unclear whether the same holds for lexical categories like V or N. Following Chomsky (2001, 11), I will here assume that it does not.
} 
realization of these functional morphemes is brought about by a post-syntactic insertion of vocabulary items - i.e., inflection markers - that pair phonological and (often underspecified) morpho-syntactic features. Affixal inflection markers presuppose complex head formation with functional and lexical morphemes. A simple assumption (and one that will do at least for present purposes) is that such complex heads are created by head movement in the syntax. This is shown schematically for $\mathrm{V}$, $\mathrm{v}$, and $\mathrm{T}$ in (2) (linear order irrelevant).

(2) [тр $\ldots$. [т $\left.[\mathrm{v} \mathrm{V} \mathrm{v}] \mathrm{T}]\left[\mathrm{vP} \ldots \mathrm{t}_{v}\left[\mathrm{vP} \ldots \mathrm{t}_{V} \ldots\right]\right]\right]$

The insertion of vocabulary items into functional heads takes place in accordance with the Subset Principle, which can be defined as in (3) (see Halle (1997), among many others).

(3) Subset Principle:

A vocabulary item $V$ is inserted into a functional morpheme $M$ iff (i) and (ii) hold:

(i) The morpho-syntactic features of $V$ are a subset of the morpho-syntactic features of $M$.

(ii) $V$ is the most specific vocabulary item that satisfies (i).

The Subset Principle contains two clauses: The first one ensures that an inflection marker can only be inserted if it is compatible with the morpho-syntatic feature specification of the syntactic context, and the second one states that to be inserted, an inflection marker must be the most specific marker among those that are compatible (see also Wunderlich (1996)). Specificity can be defined as follows (see Lumsden (1992), Noyer (1992), Wiese (1999) for versions of this concept of specificity).

(4) Specificity of vocabulary items:

A vocabulary item $V_{i}$ is more specific than a vocabulary item $V_{j}$ iff there is a class of features $\mathbb{F}$ such that (i) and (ii) hold.

(i) $V_{i}$ bears more features belonging to $\mathbb{F}$ than $V_{j}$ does.

(ii) There is no higher-ranked class of features $\mathbb{F}^{\prime}$ such that $V_{i}$ and $V_{j}$ have a different number of features in $\mathbb{F}^{\prime}$.

Thus, to determine the degree of specificity of a vocabulary item, the rank of its morpho-syntactic features on an independently available feature hierarchy must be determined; as in Optimality Theory (see Prince \& Smolensky (2004)), quality is more important than quantitiy. The (partial) feature hierarchy that I assume here is given in (5). It follows that if there are two inflection markers that are compatible with a given syntactic context, but one bears, say, a tense feature, and the other one does not, then the Subset Principle will force insertion of the former vocabulary item.

(5) Tense $>$ Number $>$ Person

A further important assumption is that morpho-syntactic specifications of syntactic contexts (i.e., of functional morphemes, in the cases at hand) can be affected by deletion operations that take place after syntax proper (so they do not affect syntactic operations like agreement), but before morphological vocabulary insertion (see Bonet (1991), Halle \& Marantz (1993; 1994), Bobaljik (2002b), Frampton (2002)). Such impoverishment rules neutralize differences between syntactic contexts in morphology; this may effect a "retreat to the general case" because more specific morphological markers may not fit anymore into impoverished contexts, and will therefore lose out to less specific markers that still do.

Finally, I adopt the following notion of fission (see Noyer (1992), Frampton (2002), Müller (2005b); the notion of fission in Halle \& Marantz (1993) is very different).

(6) Fission:

If insertion of a vocabulary item $\mathrm{V}$ with the set of morpho-syntactic features $\beta$ takes place into a fissioned morpheme $\mathrm{M}$ with the set of morpho-syntactic features $\alpha$, then $\alpha$ is split up into $\beta$ and $\alpha-\beta$, such that (a) and (b) hold:

a. $\quad \alpha-\beta$ is available for further vocabulary insertion.

b. $\beta$ is not available for further vocabulary insertion. 
Thus, insertion of the most specific vocabulary item into a fissioned functional morpheme leaves those features of the functional head which are not matched by features of this (underspecified) vocabulary item (and thereby discharged) available for further vocabulary insertion, and so on, until there is no inflection marker left that can be inserted in accordance with the Subset Principle. This way, a subanalysis of complex inflection markers becomes possible, and agglutinative-like structures can emerge in morphological systems of the Indo-European type. I assume that the functional morpheme $\mathrm{T}$ is subject to fission in German (and that $\mathrm{v}$ is not overtly realized).

\subsection{Analysis}

Let me now develop an account of the system of verb inflection in German (see Müller (2005a) for a somewhat more comprehensive exposition). Paradigms of the three main inflection classes (weak, strong, and suppletive inflection) are given in (7).

\begin{tabular}{|c|c|c|c|c|c|}
\hline \multicolumn{3}{|c|}{$\begin{array}{l}\text { a. Weak conjugation } \\
\text { glauben ('believe') }\end{array}$} & \multicolumn{3}{|c|}{$\begin{array}{l}\text { b. Strong conjugation } \\
\text { rufen ('call') }\end{array}$} \\
\hline & Präsens & Präteritum & & Präsens & Präteritum \\
\hline $1 . \mathrm{SG}$ & glaub-e & glaub-te & $1 . \mathrm{SG}$ & ruf-e & rief \\
\hline $2 . \mathrm{SG}$ & glaub-st & glaub-te-st & $2 . \mathrm{SG}$ & ruf-st & rief-st \\
\hline $3 . \mathrm{SG}$ & glaub-t & glaub-te & 3.SG & ruf-t & rief \\
\hline 1.PL & glaub-en & glaub-te-n & $1 . \mathrm{PL}$ & ruf-en & rief-en \\
\hline 2.PL & glaub-t & glaub-te-t & 2.PL & ruf-t & rief-t \\
\hline 3.PL & glaub-en & glaub-te-n & 3.PL & ruf-en & rief-en \\
\hline
\end{tabular}

c. Suppletive conjugation sein ('be')

\begin{tabular}{|l||l|l|}
\hline & Präsens & Präteritum \\
\hline $1 . \mathrm{SG}$ & bin & war \\
\hline $2 . \mathrm{SG}$ & bi-st & war-st \\
\hline $3 . \mathrm{SG}$ & is-t & war \\
\hline $1 . \mathrm{PL}$ & sind & war-en \\
\hline $2 . \mathrm{PL}$ & seid & war-t \\
\hline 3.PL & sind & war-en \\
\hline
\end{tabular}

These paradigms exhibit four instances of syncretism that I take to be non-accidental, and in need of an explanation. First, the inflection markers for 1.SG.PAST and 3.SG.PAST contexts are identical in all paradigms. Second, the inflection markers for 1.PL and 3.PL contexts are identical in all tenses and paradigms. Whereas these two instances of syncretism are straightforward and evidently systematic, the remaining two may at first sight look less obvious: The marker for 3.SG.PrES is $t$, and the very same markers shows up in 2.PL.PrES contexts in the two main inflection classes in (7-ab). Finally, the marker for 2.SG contexts $(s t)$ is identical throughout to the marker for 3.SG.PRES contexts $(t)$, except for the initial $s$.

Of these four cases of syncretism, only the first two have been accounted for in the literature (see Wiese (1994), Wunderlich (1996), and Eisenberg (2000)); however, they have not been derived as the general, system-wide properties that they arguably are, but rather as the result of individual inflection marker specifications of an arbitrary nature. To the best of my knowledge, the remaining two syncretisms have not yet been systematically addressed. ${ }^{3}$

The analysis I would like to propose is based on three building blocks: First, standard morphosyntactic features are decomposed into combinations of more abstract primitive features. A crossclassification of these features yields the standard morpho-syntactic categories; and underspecifica-

\footnotetext{
${ }^{3}$ Compare, however, the remarks in Bierwisch (1961, 62-66) on the third syncretism involving marker homonymy in 3.SG.PRES and 2.PL.PRES contexts. Also relevant are the empirical results reported in Fanselow \& Frisch (2005), according to which DP coordinations with oder ('or') that involve agreement with the same finite verb and exhibit this syncretism are judged grammatical by speakers (see (i-a)), on a par with coordination examples that involve an instance of syncretism that is uncontroversially systematic (see (i-b)), but in contrast to minimally different coordination examples that do not involve a syncretism in the verb form (see (i-c)).
}

(i) a. Er oder ihr wohnt in Frankfurt he or you.PL live-3.SG.PRES/2.PL.PRES in Frankfurt

b. Wir oder sie wohnen in Frankfurt

we or they live-1.PL.PRES/3.PL.PRES in Frankfurt

c. *Ich oder du wohne/wohnst in Frankfurt

I or you.Sg live-1.SG.PrES/live.2.SG.PRES in Frankfurt 
tion of inflection markers with respect to these features captures natural classes of categorizations and thereby accounts for cases of syncretism (see Bierwisch (1967), extending earlier work by Jakobson (1962)). More specifically, I assume that the person features 1., 2., 3., and 1.INCL(USIVE) are to be decomposed into combinations of the more primitive features $[ \pm 1],[ \pm 2]$, as shown in (8) (see Noyer (1992), Wiese (1994), Wunderlich (1996), Frampton (2002)). It follows that (i.a.) 1. and 3. form a natural class (characterized by the underspecified information [-2]), as do 2. and 3. (characterized by [-1]). Consequently, we expect syncretism to affect 1./2. and 2./3. categorizations, but not 1./2. or 1.INCL/3. categorizations. ${ }^{4}$

(8) Decomposition of person features:
a. $1=[+1,-2]$
b. $1 . \mathrm{INCL}=[+1,+2]$
c. $2=[-1,+2]$
d. $3=[-1,-2]$

Second, fission ensures that $s t$, which at first sight looks like a single inflection marker without internal structure, can emerge as the combination of two vocabulary items $/ \mathrm{s} /$ and $/ \mathrm{t} /$, inserted in that order. Third, impoverishment also refers to natural classes of persons and can thus derive system-wide syncretism patterns. For concreteness, suppose that the two impoverishment rules in (9) apply to T morphemes in German.

(9) Impoverishment rules for German verb inflection:

a. $[ \pm 1] \rightarrow \varnothing /[-2,-$ pl, + past $]$

b. $\quad[ \pm 1] \rightarrow \varnothing /[-2,+\mathrm{pl}]$

Both impoverishment rules neutralize $\phi$-feature distinctions: Rule (9-a) ensures that it is a defining property of the system of verb inflection in German that 1. and 3. SG.PAST contexts cannot have a different morphological realization, whatever the inflection class otherwise looks like; this is so because the sole feature that differentiates 1 . and 3. person is deleted $([ \pm 1])$. Similarly, rule $(9-b)$ has the effect of systematically neutralizing the syntactic difference between 1 . and 3. person in the plural in general. Hence, the only domains where 1. and 3. person can be (and regularly are) distinguished are SG.PRES contexts. ${ }^{5}$

Given these assumptions, the set of inflection markers for Theads in (10) accounts for all instances of syncretism in German verb inflection (abstracting away from suppletion here and in what follows). ${ }^{6}$

(10) Vocabulary items:
a. $/$ te/ $\leftrightarrow[+$ past,-strong]
b. $/ \mathrm{s} / \leftrightarrow[+2,-\mathrm{pl}]$
c. $/ \mathrm{n} / \leftrightarrow[-2,+\mathrm{pl}]$
d. $/ \mathrm{t} / \leftrightarrow[-1]$
e. $/(\mathrm{e}) / \leftrightarrow[\mathrm{]}$

\footnotetext{
${ }^{4}$ Of course, 1.INCL is a categorization that is not actually used in Indo-European languages; but the feature system is designed to be more general.

${ }^{5}$ The effects of impoverishment rules can be imitated by rules of referral as they have been employed in recent Wordand-Paradigm approaches (see Stump (2001) and references cited there), and by optimization procedures (see Prince \& Smolensky (2004)) that give rise to optimal unfaithful feature specifications (with non-fatal MAX violations), as they have beeen argued for in recent versions of Minimalist Morphology (see, e.g., Wunderlich (2004)). However, of these three means to derive system-wide patterns of syncretism, impoverishment seems to be the most restrictive one since it is standardly taken to be only able to bring about feature deletion. In contrast, rules of referral can effect feature deletion, feature insertion, feature change, and much more; and optimization procedures based on ranked and violable constraints can bring about feature deletion (violations of MAX constraints), feature insertion (violations of DEP constraints), and feature change (violations of IDENT constraints).

${ }^{6}$ The //-notation is supposed to indicate that the markers are abstract items that may undergo certain (morpho-) phonological changes.
} 
The most specific marker is the past tense marker for the weak inflection class, /te/. It is inserted wherever it is compatible with the fully specified syntactic feature context in T (cf. (3)), discharging the features [+past] and [-strong] in accordance with (6). The two next specific vocabulary items are $\mathrm{s} /$ and $/ \mathrm{n} /$ (since they bear number features, unlike the remaining items): $/ \mathrm{s} /$ is a singular marker for 2. person, and $/ \mathrm{n} /$ is a plural marker for non-2. person - an option made possible by person feature decomposition (more specifically, the availability of the feature [-2]) and underspecification. These two markers are then inserted wherever possible, discharging the matching features in T. The next specific marker is $/ \mathrm{t} /$. It is then inserted in all contexts in which the specification [-1] is available. Since the more specific markers do not bear the feature [-1], their insertion cannot possibly have led to a discharge of $[-1]$. However, the case is different with the impoverishment rules in (9), which both delete [-1] (and [+1]) in [-2] contexts, except for the SG.PrES domain. Consequently, /t/ is inserted in all 2. and 3. person contexts, except for those 3. person contexts that are subject to pre-morphological impoverishment. As a result, the /t/ in Er glaub- $t$ ('He believes') and the $/ \mathrm{t} / \mathrm{in}$ Du glaub-s-t ('You.SG. believe') emerge as one and the same marker. Finally, the least specific (in fact, radically underspecified) vocabulary item /(e)/ acts as a default marker that can in principle be inserted anywhere. I assume that such radically underspecified markers are inserted iff there is no other marker in the functional morpheme. ${ }^{7}$ Furthermore, the vocabulary item /(e)/ is somewhat more abstract than the other markers in (10) in the sense that it requires a minimal indication of deviation from the present tense stem. Hence, $/(\mathrm{e}) / \rightarrow \emptyset$ whenever there is stem alternation in past tense contexts (strong verbs); and /(e)/ $\rightarrow e$ in present tense contexts when there is no other marker. The paradigm of verb inflection in German that arises in this way is shown in (11).

(11) Vocabulary insertion into impoverished Ts in German

\begin{tabular}{|c|c|c|c|c|c|}
\hline $\mathrm{T}$ & $\begin{array}{r}{[-\mathrm{p}} \\
{[- \text { strong] }} \\
\end{array}$ & $\begin{array}{l}\text { ast }] \\
{[+ \text { strong }]}\end{array}$ & $\mathrm{T}$ & $\begin{array}{r}{[+1} \\
{[- \text { strong }]}\end{array}$ & $\begin{array}{l}\text { ast] } \\
\text { [+strong] }\end{array}$ \\
\hline$[+1,-2,-\mathrm{pl}]$ & /e/ & /e/ & {$[ \pm 1,-2,-\mathrm{pl}]$} & /te/ & $\varnothing$ \\
\hline$[-1,+2,-\mathrm{pl}]$ & $/ \mathrm{s} /-\mathrm{t} / \mathrm{s}$ & $/ \mathrm{s} /-\mathrm{t} / \mathrm{s}$ & {$[-1,+2,-\mathrm{pl}]$} & $/$ te/-/s/-/t/ & $/ \mathrm{s} /-\mathrm{t} / \mathrm{s}$ \\
\hline$[-1,-2,-\mathrm{pl}]$ & $/ \mathrm{t} /$ & $/ \mathrm{t} /$ & {$[=1,-2,-\mathrm{pl}]$} & /te/ & $\varnothing$ \\
\hline$[ \pm 1,-2,+\mathrm{pl}]$ & $/ \mathrm{n} /$ & $/ \mathrm{n} /$ & {$[ \pm 1,-2,+\mathrm{pl}]$} & /te/-/n/ & $/ \mathrm{n} /$ \\
\hline$[-1,+2,+\mathrm{pl}]$ & $/ \mathrm{t} /$ & $/ \mathrm{t} /$ & {$[-1,+2,+\mathrm{pl}]$} & $/ \mathrm{te} /-/ \mathrm{t} /$ & $/ \mathrm{t} /$ \\
\hline$[=1,-2,+\mathrm{pl}]$ & $/ \mathrm{n} /$ & $/ \mathrm{n} /$ & {$[=1,-2,+\mathrm{pl}]$} & $/ \mathrm{te} /-/ \mathrm{n} /$ & $/ \mathrm{n} /$ \\
\hline
\end{tabular}

This may suffice as an exposition of the gist of German verb inflection under the present analysis. It is worth emphasizing that the two impoverishment rules in (9) play a fundamental role in this approach. They account for the fact that there are system-wide patterns of syncretism in (7); and they are crucial if a maximally simple inventory of inflection markers in (10) is to be posited, with only one meaning (i.e., feature specification) for any given form (i.e., phonological information). What is more, the approach in terms of impoverishment is corroborated by diachronic evidence. Identity of inflection markers for 1.PL.PAST and 3.PL.PAST (as well as for 1./3.SG.PAST forms; see below) is also a property of the Middle High German system of verb inflection; however, identity of 1.PL.PRES and 3.PL.PRES is not yet. This is accounted for if $\phi$-feature impoverishment was confined to past contexts in Middle High German, and has then been extended to present plural contexts on the way to Modern German. Interestingly, the marker for 3.PL.PRES contexts was $/ \mathrm{n} / / \mathrm{t} / \mathrm{in}$ Middle High German, and this is exactly what we expect it to be under the present analysis: If there is no impoverishment rule deleting $[-1]$ in 3.PL contexts, /t/ is predicted to show up. Thus, we find hélfen (1.PL.PrEs, 'we help') alongside hélfent (3.PL.PRES, 'they help').

\footnotetext{
${ }^{7}$ This also precludes unwanted iteration of /(e)/-insertion, as it would otherwise be wrongly predicted to be possible under (6); also compare Wunderlich's (1996) Monotonicity Principle.
} 


\section{A Failed Attempt}

Returning to the issue of pro-drop, I would like to contend that it is the existence of impoverishment rules of the type in (9) that makes argumental pro-drop impossible in German and other languages without licensing of subject pro (i.e., such $\phi$-feature impoverishment is responsible for the lack of sufficient morphological richness). However, if nothing else is said, this reasoning leads to a dilemma.

As has been observed by Bobaljik (2002a), properties of the morphological inventory cannot be held responsible for the operation of V-to-T movement in syntax if inflectional morphology is post-syntactic: The hypothesis according to which V-to-T movement takes place if a language has a morphological system of verbal inflection that is sufficiently rich (see Roberts (1993), Vikner (1997), Holmberg \& Platzack (1995), and Rohrbacher (1999) for various suggestions that differ in detail but converge on the general idea) must therefore be given up in a Distributed Morphology approach. If there is any synchronically relevant correlation at all (see Alexiadou \& Fanselow (2000)), it must go in the other direction: Rich verbal morphology can be a reflex of movement, but not the reason for it. Bobaljik (2002a) argues that this is the correct result for V-to-T movement.

Evidently, the same situation occurs with licensing of pro: Assuming post-syntactic morphology, pro-licensing cannot be determined by morphological properties (like size of the morphological inventory, or, as I want to argue here, presence or absence of $\phi$-feature neutralizing impoverishment operations) because these properties are not yet visible at the point of the derivation where they would be needed. Consequently, given a post-syntactic morphology, there are only two possibilites as far as the interaction with pro-drop is concerned: The first possibility is that pro-drop is a syntactic phenomenon which is independent of the properties of morphological inventories; see, e.g., Grimshaw \& Samek-Lodovici (1998). ${ }^{8}$ The second possibility is that pro-drop is a post-syntactic (PF) phenomenon (see, e.g., Adger (2003), Holmberg (2004)). Both options strike me as worth pursuing in principle. Still, in what follows I presuppose that a case can be made for the standard view that pro-drop is determined by the morphological properties of verb inflection systems, and that it is a syntactic phenomenon involving the licensing of an argumental empty category pro (see Rizzi (1986) and Jaeggli \& Safir (1989), among many others). How, then, can the dilemma sketched above be solved?

I suggest that it can be solved if we give up the assumption that inflectional morphology is postsyntactic, and make the opposite assumption that inflectional morphology is pre-syntactic. If so, impoverishment will be pre-syntactic too, and the relevant morphological information (i.e., whether or not T has been affected by $\phi$-feature impoverishment) is available when the syntactic decision on pro-licensing must be made. It then remains to be shown that a pre-syntactic approach to inflectional morphology that incorporates essential features of Distributed Morphology (underspecification, fission, and, especially, impoverishment) is both tenable and independently supported. I address this issue in the following section.

\section{Pre-Syntactic Morphology}

Given optimal design considerations (see Chomsky (2001; 2005)), a system of inflectional morphology that relies on post-syntactic vocabulary insertion looks like an imperfection. A first potential conceptual problem is that inflection markers are split into two separate units (f-morpheme and vocabulary item). A second one is that the insertion operation as such is clearly very different in nature and scope from the few elementary operations that are adopted in the minimalist program (Merge and Agree, perhaps also Move); it seems that the null hypothesis should be that the elementary operations of syntax are also active in morphology, and specific morphological operations like vocabulary inser-

\footnotetext{
${ }^{8}$ More generally, this would seem to be the standard approach in optimality-theoretic syntax; see also Vikner (2001a) on V-to-T movement. Alternatively, optimality-theoretic analyses may treat morphological marking as a reflex of syntax (see, e.g., Legendre et al. (1998) on the general issue, and Müller (2002) on the correlation of morphological richness and free word order). However, the idea of morphology-driven syntax seems to be much harder to reconcile with basic optimality-theoretic assumptions (but see Vikner (2001b) for a recent attempt).
} 
tion can be dispensed with. Finally, a third conceptual problem with late insertion is that it cannot possibly satisfy two highly general and independently motivated constraints (see Chomsky (1995; $2000 ; 2001)$ ) at the same time: the Inclusiveness Condition, according to which new elements (like features) cannot be introduced in the course of the derivation, and the Legibility Condition, from which one can derive that morpho-syntactic features can be present in some component of grammar only if they are interpretable in this component. This dilemma is created by features that are relevant in morphology but irrelevant (i.e., uninterpretable) in syntax, viz., inflection class features (like $[ \pm$ strong] in the present analysis of German verb inflection). As argued in detail in Alexiadou \& Müller (2005), the Inclusiveness Condition is violated if class features are absent in syntax and added afterwards in a post-syntactic approach to inflection; and the Legibility Condition is violated if syntactically uninterpretable class features are present in syntax but only used afterwards, in the morphological component.

In view of this state of affairs, I would like to conclude that a morphological component of grammar that meets minimalist requirements should be pre-syntactic rather than post-syntactic. However, there does not seem to be a good reason to give up successful concepts like underspecification, fission, and impoverishment under this changed perspective. With respect to underspecifcation, the case is simple because the issue is orthogonal to the timing of inflection (pre-, post-, or intra-syntactic); accordingly, there are pre-syntactic approaches to morphology that embrace this concept (see, e.g., Wunderlich (1996)). With respect to fission and impoverishment, the issue turns out to be slightly more involved. The first outlines of a pre-syntactic morphology that satisfies minimalist goals have been sketched in Alexiadou \& Müller (2005). I will use this approach as a point of departure, and then integrate the concepts of fission and impoverishment into it.

The main assumption is that (inflectional) morphology takes place in a generative component of grammar that follows the lexicon but precedes syntax. Assuming the minimalist program, a natural assumption then is that inflectional morphology is located in the numeration (cf., e.g., Chomsky $(1995 ; 2000)$ for this notion). ${ }^{9}$ Pre-syntactic inflection in the numeration is assumed to be driven by (syntactically) uninterpretable material, viz., inflection class features. As regards verb inflection, suppose that inflection class features, which are inherent to a stem, are borne by V (note that these features may in principle be trivial if there is only one inflection class in the language; see Aronoff (1994)). In contrast, non-inherent features relevant for verb inflection in German (tense features, mood features, and, in particular, $\phi$-features) are freely instantiated on $\mathrm{T}$ as $\mathrm{T}$ enters the numeration. Together, these sets of fully specified features provide the context. An uninterpretable class feature on $\mathrm{V}$ then acts as a probe; it triggers an Agree operation with a matching inflection marker (i.e., a compatible inflection marker, which does not have to be equipped with a class feature itself), which leads to Merge of $\mathrm{V}$ and the inflection marker (selection requirements ensure that it is $\mathrm{V}$ rather than $\mathrm{T}$ that is affected by Merge of the inflection marker). All of the inflection marker's features (including underspecified $\phi$-features) are inherent. The effects of the Subset Principle follow if we make the (standard) assumption that Agree requires feature matching (see the compatibility requirement in (3)(i)), and the more specific assumption that Agree also requires a maximization of matching effects (see Chomsky $(2001,15))$. We may understand the latter condition in such a way that as many high-ranked features are affected by an Agree operation as possible, where quality outranks quantity (see the specificity requirement in (3)-(ii), (4)). Thus, the most specific compatible inflection marker is used in pre-syntactic Agree-driven Merge operations that bring about verbal inflection. ${ }^{10}$ We can then further

\footnotetext{
${ }^{9}$ Chomsky $(2000 ; 2001)$ assumes that numerations are split up into lexical subarrays; these contain the lexical material that shows up in a phase ( $\mathrm{vP}$ or $\mathrm{CP}$ ). As will become clear shortly, morphological operations cannot be confined to the subarray under present assumptions, unless we assume that $\mathrm{T}$ and $\mathrm{V}$ may belong to the same subarray (hence, the same phase; see Richards (2004) for such a proposal). The reason is that $\mathrm{T}$ and $\mathrm{V}$ will both emerge as relevant for verb inflection. Consequently, the local domain for pre-syntactic morphology must either be the complete numeration, or, more likely, a subpart of it that corresponds to Grimshaw's (2000) extended projection of V (including T).

${ }^{10}$ Where do the inflection markers that are required by class feature probes come from? There are at least two options.
} 
assume that syntactically uninterpretable features of $\mathrm{V}$ (inflection class), and all morpho-syntactic features of the inflection marker (typically underspecified - hence, syntactically uninterpretable information), are deleted in morphology; syntactically interpretable features of $\mathrm{V}$ and all features of $\mathrm{T}$ remain unaffected. Finally, the items of the numeration (inflected $\mathrm{V}, \mathrm{v}, \mathrm{T}, \ldots$ ) enter syntax, bearing only fully specified and syntactically interpretable morpho-syntactic features.

At this point, the question arises how fission and impoverishment can be integrated into the approach. As concerns the former concept, I would like to suggest that it is the defining property of fission that a class feature probe that has triggered an Agree operation does not delete immediately, but may trigger further Agree operations, and only deletes when no further Agree operation is possible anymore. That leaves impoverishment. Impoverishment can be viewed as a pre-syntactic operation, provided that the features that are affected are invisible for morphology, but not for subsequent syntactic operations (e.g., a [-1] feature that is affected by impoverishment in German must still be visible in syntax, where 1. and 3. person can be distinguished in all numbers and tenses). On this view, impoverishment of $\mathrm{T}$ applies in the morphological component after T's non-inherent features have been added, but before Agree with an inflection marker is carried out. Thus, suppose that impoverishment marks features as morphologically unaccessible, but it does not actually delete them, and they remain accessible in syntax. ${ }^{11}$ As an example of how this system of pre-syntactic verb inflection in German works, consider the following derivation of glaubten ('believe.3.PL.PAST') in the numeration: ${ }^{12}$

(12) a. Selection of glaub: $\{\mathrm{V},[-$ strong $]\}$ from the lexicon.

b. Selection of $\mathrm{T}$ from the lexicon; addition of fully specified $\phi$ - and tense features:

$\mathrm{T}:\{[-1,-2,+\mathrm{pl},+$ past $]$

c. Application of impoverishment rule (9-b) to $\mathrm{T}$ :

$\mathrm{T}:\{[-1,-2,+$ pl,+past $] \rightarrow \mathrm{T}:\{[=1,-2,+$ pl,+past $]$

d. Agree-driven Merge of (matching, most specific) /te/ with V:

glaub: $\{\mathrm{V},[$-strong $]\}, \mathrm{T}:\{[-1,-2,+$ pl, + past $]\}+/$ te $/:\{[+$ past,-strong $]\} \rightarrow$ glaub-te: $\{\mathrm{V},[-$ strong $]\}, \mathrm{T}:\{[=1,-2,+\mathrm{pl},+$ past $]\}$

e. Agree-driven Merge of (matching, next specific) /n/ with V: glaub-te: $\{\mathrm{V},[-$ strong $]\}, \mathrm{T}:\{[-1,-2,+\mathrm{pl},+$ past $]\}+/ \mathrm{n} /:\{[-2,+\mathrm{pl}]\} \rightarrow$

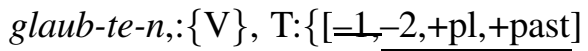

f. $\quad T$ and the inflected $V$ enter syntax, with all remaining morpho-syntactic features (whether affected by impoverishment, affected by Agree, or not affected at all) accessible to syntactic operations.

To sum up so far, we have to main results. First, $\phi$-feature impoverishment plays an important role in verb inflection (section 2). And second, $\phi$-feature impoverishment can and, given basic tenets of the minimalist program, arguably should be conceived of as a pre-syntactic operation (section 4). With these results in place, we are now in a position to give a principled answer to the question why some languages exhibit subject argument pro-drop, and others do not.

One option is that they may simply be taken out of the lexicon when the need arises. This implies that operations in the numeration can still have access to the lexicon (and carry out search in the lexicon, selecting the most specific compatible item). Alternatively, the complete inventory of inflection markers of a given type (e.g., realization for V-T in German) may enter the numeration as a single set, and the inflection operations picks out one item of this set. This implies that not all material that enters a numeration will have to be used in the syntactic derivation.

${ }^{11}$ Note that this is parallel to Chomsky's (1995) distinction between deletion and erasure.

${ }^{12}$ Impoverished features are struck through; discharged features fission contexts are underlined. 


\section{Proposal}

As indicated above, I suggest that whether or not subject argument pro is licensed by $\mathrm{T}$ depends on whether or not $\mathrm{T}$ is affected by a certain type of impoverishment operation in the numeration. ${ }^{13}$ More specifically, I would like to advance the following generalization: ${ }^{14}$

\section{(13) Pro Generalization:}

An argumental pro DP cannot undergo Agree with a functional head $\alpha$ if $\alpha$ has been subjected (perhaps vacuously) to $\phi$-feature neutralizing impoverishment in the numeration.

The $\phi$-feature that is relevant in the present context is the person feature; one might speculate that it is cross-linguistically only this feature which is relevant for determining pro-drop (see Rohrbacher (1999)). We can say that an impoverishment rule is " $\phi$-feature neutralizing" in the sense of (13) when a distinction between two $\phi$-categorizations - e.g., 1 . person $([+1,-2])$ vs. 3 . person $([-1,-2])$ cannot be made anymore. As a consequence of (13), only a system-defining syncretism (i.e., one that is derived by impoverishment) can preclude the licensing of pro by $\mathrm{T}$. In contrast, syncretisms that are solely due to underspecification of particular inflection markers, as well as accidental homonomies, cannot block pro licensing.

With respect to German, it is now clear why the language does not exhibit subject argument pro (see (1-d)) even though at first glance it seems to have a fairly rich system of verb inflection (see (7)): The reason is that German has the two impoverishment rules in (9), which neutralize $\phi$-feature distinctions (and only one of the rules would have been sufficient to preclude pro-drop). Given that each $\mathrm{T}$ head is affected by these two rules in the numeration (perhaps vacuously so, e.g., if $\mathrm{T}$ is specified as [+2], or as [-pl,-past]), there is no $\mathrm{T}$ which esacpes the weakening effect of impoverishment, and subject argument pro is correctly predicted to be impossible throughout in this language.

In the remainder of this paper, I will briefly discuss three languages that are relevant for the main hypothesis, for different reasons. First, Icelandic is renowned among the Germanic languages for its rich inflectional morphology; still, it does not permit subject argument pro. Second, Modern Irish presents the reverse situation: The system of verb inflection is fairly poor, but pro is licensed. Finally, I discuss Russian, which raises interesting questions concerning both pro-drop and impoverishment.

\subsection{Icelandic}

Subject argument pro-drop is not possible in Icelandic (except for questionable instances of pro-drop with meteorological precicates); see (14) (cf. Platzack (1987), Holmberg \& Platzack (1995), and Rohrbacher (1999)).
a. Hann dansar
he dance-3.SG
b. *pro dansar
dance-3.SG

We are thus led to expect that Icelandic verb inflection is not morphologically rich. However, a superficial look at the actual paradigms does not confirm this expectation. Consider, e.g., the paradigms in (15) (see Kress (1982)), which illustrate three arbitrarily selected inflection classes (two weak, one strong); all conjugations employ a rich inventory of inflection markers.

\footnotetext{
${ }^{13}$ Note that this information can be checked locally for every single $\mathrm{T}$ head in the numeration, which avoids a further problem typically faced by paradigm-based approaches to morphological richness and pro-drop, viz.: How can a global property of the language (richness of verb inflection) be encoded as a local property of the actual head that licenses pro?

${ }^{14}$ This generalization may ultimately follow from more basic principles, but I will not pursue this matter here.
} 
(15)

Weak conjugation, class 1
krefja ('demand')
\begin{tabular}{|l||l|l|}
\hline & present & past \\
\hline $1 . S G$ & kref & krafði \\
\hline $2 . S G$ & krefur & krafðir \\
\hline $3 . S G$ & krefur & krafði \\
\hline $1 . P L$ & krefjum & kröfðum \\
\hline $2 . P L$ & krefjið & kröfðuð \\
\hline $3 . P L$ & krefja & kröfðu \\
\hline
\end{tabular}

Weak conjugation, class 4

dansa ('dance')

\begin{tabular}{|l||l|l|}
\hline & present & past \\
\hline $1 . S G$ & dansa & dansaði \\
\hline $2 . S G$ & dansar & dansaðir \\
\hline $3 . S G$ & dansar & dansaði \\
\hline $1 . P L$ & dönsum & dönsuðum \\
\hline $2 . P L$ & dansið & dönsuðuð \\
\hline 3.PL & dansa & dönsuðu \\
\hline
\end{tabular}

Strong conjugation, class 3

sleppa ('slip')

\begin{tabular}{|l||l|l|}
\hline & present & past \\
\hline $1 . \mathrm{SG}$ & slepp & slapp \\
\hline $2 . \mathrm{SG}$ & sleppur & slappst \\
\hline 3.SG & sleppur & slapp \\
\hline $1 . \mathrm{PL}$ & sleppum & sluppum \\
\hline 2.PL & sleppið & sluppuð \\
\hline 3.PL & sleppa & sluppu \\
\hline
\end{tabular}

However, under the perspective adopted here, the decisive question is not whether Icelandic verb inflection uses a rich set of morphological markers, but rather, whether there are system-wide patterns of syncretism that can be traced back to pre-syntactic impoverishment operations. And indeed, there are: On the one hand, the inflection markers for 1.SG.PAST and 3.SG.PAST contexts are identical in all inflection classes; i.e., the situation is exactly as in German in this respect. Accordingly, we can postulate the impoverishment rule in (16-a), which deletes $[ \pm 1]$ in SG.PAST contexts and thereby renders 1. and 3. person indistinguishable in these environments (see Frampton (2002)). On the other hand, it turns out that 2.SG.PRES and 3.SG.PRES contexts also have identical morphological realizations in all conjugations. This, too, can be captured straightforwardly by postulating a simple impoverishment rule because 2. person and 3. person form a natural class (captured by [-1]) under the decomposition of person features in (8). Thus, (16-b) deletes [ \pm 2$]$ in SG.PRES contexts; as a result, there can be no morphological differentiation between 2. and 3. person in this environment. ${ }^{15}$

(16) Impoverishment rules for Icelandic verb inflection:

a. $\quad[ \pm 1] \rightarrow \varnothing /[-2,-$ pl,+past $]$

b. $\quad[ \pm 2] \rightarrow \varnothing /[-1,-$ pl,-past $]$

As a consequence of these impoverishment rules affecting all $\mathrm{T}$ heads in the numeration, subject argument pro cannot be licensed in Icelandic, despite its seemingly "rich" verb inflection. Note that this conclusion is independent of the actual feature specifications for inflection markers that underlie the paradigms in (15). ${ }^{16}$

More generally, we can note that all Germanic languages, beginning with the earliest records, exhibit what looks like a system-wide syncretism in 1. and 3.SG.PAST contexts. Consequently, the prediction would seem to be that they all do not permit subject argument pro-drop. Whereas this conclusion is fairly uncontroversial with regard to the modern Germanic languages, there is some disagreement as to whether or not subject argument pro-drop is possible in the older Germanic languages; in particular, the question arises for Gothic, Old Norse, Old High German, and Old English. In these languages, there are cases where subject argument pronouns can be left without phonological realization (see Abraham (1991), Gelderen (2000), and Axel (2004)); however, the distribution of these instences of argument omission is quite different from what is otherwise known for subject argument pro-drop, particularly so in Old High German and in Old English. I will have to leave this issue unresolved here, the simple options of analysis at this point being to assume (i) that pro is not licensed in one or more of the languages under consideration, and/or (ii) that the general nature of the 1./3.SG.PAST syncretism has not yet become manifest in a system-defining impoverishment

\footnotetext{
15 The same impoverishment rule may also take effect in Brazilian Portuguese (with identity of markers for 2. and 3. person) vs. European Portuguese (with two different markers for 2. and 3. person), and account for the rapid decline of pro-drop in the former. See Rohrbacher (1999, 246-250) for discussion.

${ }^{16}$ I do not attempt to provide a full-fledged analysis of Icelandic verb inflection here; suffice it to say that the concepts of underspecification and fission strongly suggest themselves for this system, too. (Consider, e.g., the distribution of theme vowels in inflectional endings - an alternation like /u/-/r/, /a/-/r/, /i///r/ in 2. person contexts clearly argues for a subanalysis of the markers, and thus lends itself to an approach in terms of fission.)
} 
rule in one or more of the relevant languages. Still, in this context it is instructive to note that the domain in which system-wide patterns of syncretism can be found in verb inflection grows steadily from the earliest records in Gothic and Old High German (1./3.SG.PAST realizations are identical) through Middle High German (1./3.SG.PAST and 1./3.PL.PAST realizations are identical) to Modern German (1./3.SG.PAST, 1./3.Pl.PAST, and 1./3.PL.Pres realizations are identical); in the present approach, this corresponds to a proliferation of impoverishment rules. Concurrently, subject argument omission becomes more and more restricted.

\subsection{Modern Irish}

Modern Irish exhibits subject argument pro-drop; cf. (17) (from McCloskey \& Hale (1984, 488).

Dá gcuirfeá pro isteach ar an phost sin gheobhfá pro é
if put-2.SG.COND in on that job get-2.SG.COND it
'If you applied for that job, you would get it."

However, the system of verb inflection does not qualify as morphologically rich under standard assumptions, and this poses a problem for approaches in which the number of distinct inflection markers in paradigms determines whether or not subject argument pro-drop is possible (see McCloskey \& Hale (1984) and Jaeggli \& Safir (1989)). Consider the conditional paradigm and the present indicative paradigm of the verb cuir ('put') in (18), which contain so-called analytic and synthetic forms; only the latter permit subject pro-drop. The analytic forms are chuirf-eadh and chuir-eann, respectively. The conditional paradigm has three different synthetic forms, the indicative paradigm only one. Thus, both German and Icelandic have a larger inventory of verb inflection markers.

\begin{tabular}{|c|c|c|c|c|}
\hline & \multicolumn{2}{|c|}{$\begin{array}{l}\text { Conditional conjugation } \\
\text { cuir ('put') }\end{array}$} & \multicolumn{2}{|c|}{$\begin{array}{l}\text { b. Inditicative conjugation } \\
\text { cuir ('put') }\end{array}$} \\
\hline & $1 . \mathrm{SG}$ & chuirf-inn & $1 . \mathrm{SG}$ & chuir-im \\
\hline & $2 . S G$ & chuirf-ea & $2 . \mathrm{SG}$ & chuir-eann \\
\hline & 3.SG.MASC & chuirf-eadh & 3.SG.MASC & chuir-eann \\
\hline & 3.SG.FEM & chuirf-eadh & 3.SG.FEM & chuir-eann \\
\hline & $1 . \mathrm{PL}$ & chuirf-imis & $1 . \mathrm{PL}$ & chuir-eann \\
\hline & 2.PL & chuirf-eadh & $2 . \mathrm{PL}$ & chuir-eann \\
\hline & $3 . \mathrm{PL}$ & chuirf-eadh & $3 . \mathrm{PL}$ & chuir-eann \\
\hline
\end{tabular}

Modern Irish verb inflection raises several problems for morphological analysis. For instance, it is not quite clear whether the analytic forms in (18) should be treated on a par with the synthetic forms in morphology, as involving radically underspecified default markers (on this general view, the markers cannot be partially underspecified with respect to $\phi$-features because the occurrences of the analytic forms do not form a natural class); whether we are dealing with genuine paradigmatic gaps here that are filled by external forms; or whether some kind of blocking is involved. However, even assuming that the first analysis is on the right track, i.e, that the syncretism in (18) is due to radical underspecification in both cases, it seems clear that there are no general, system-defining impoverishment rules involved that would give rise to trans-paradigmatic patterns. Consequently, the availability of subject argument pro-drop with the synthetic forms is expected under present assumptions, even though "Irish is not a language which is in any general sense rich in its system of person-number marking morphology for verbs" (McCloskey \& Hale $(1984,492)) .{ }^{17}$

\subsection{Russian}

Consider the present tense paradigm of Russian verb inflection in (19).

\footnotetext{
${ }^{17}$ More must eventually be said about the absence of pro-drop with the analytic forms; but any such analysis will have to clarify the morphological questions just mentioned in the main text first.
} 
(19) Present tense conjugation:

čitat' ('read')
\begin{tabular}{|l||l||l|}
\hline $1 . S G$ & čita-ju \\
\hline $2 . S G$ & čita-eš' \\
\hline $3 . S G$ & čita-et \\
\hline
\end{tabular}$\quad$\begin{tabular}{|l|l|}
\hline $1 . P L$ & čita-em \\
\hline $2 . P L$ & čita-ete \\
\hline $3 . P L$ & čita-jut \\
\hline
\end{tabular}

There is no syncretism here; hence, there can be no impoverishment rule underlying the Russian system of verb inflection in the present tense. Based on this evidence, we may expect subject argument pro-drop to occur in Russian. And indeed, relevant examples are typically well formed; see, e.g., (20).

$$
\begin{gathered}
\text { pro ponimaju } \\
\text { understand-1.SG.PRES } \\
\text { [CP čto [tp pro imeeš }
\end{gathered}
$$

Accordingly, it has often been suggested that Russian permits subject argument pro licensing (see, e.g., Růžička (1986), Müller (1988), Demjjanow \& Strigin (2000), Perlmutter \& Moore (2002)). However, there is also a different view that holds that subject argument pro is not possible in Russian (see, e.g., Franks (1995, ch. 7), Avrutin \& Rohrbacher (1997), and Junghanns (2005)); on this latter view, instances of subject argument omission as in (20) are instances of contextually licensed ellipsis. Among the main reasons for not assuming Russian to have regular subject pro is the fact that "prodrop in Russian is subject to discourse conditions that make it much less common than pro-drop in Italian or Spanish" (see Perlmutter \& Moore (2002, 632)), or, for that matter, in other Slavic languages like Czech or Polish; in particular, Russian differs from some other pro-drop languages in that overt subject pronouns can be unmarked in non-emphatic contexts. Furthermore, as noted by Růžička (1986), there is an asymmetry between 1./2. and 3. person pro-drop, with the latter option emerging as more marked (a similar situation obtains in Hebrew, though). However, I do not consider these (and other) arguments to be convincing counter-evidence to the hypothesis that Russian has subject argument pro licensing by $\mathrm{T}$; and I believe there is at least one strong argument in support of a pro analysis of subject argument omission in finite clauses in Russian (see Müller (1988, 98-100)). It turns out that in some cases, using pro is in fact the only possibility to achieve a certain reading of a sentence; the counterpart with a phonologically realized pronoun necessarily means something else. The generic interpretation of subject argument pronouns as 'one' is a case in point. The examples in (21) can all have a generic interpretation of the subject pronoun argument; this reading is not available when the pronoun is overtly realized (see Suñer (1983) for the same effect in Spanish). It seems clear that a PF-approach in terms of contextually licensed ellipsis cannot possibly be held responsible for the generic interpretation of the 2.SG. and 3.PL subject arguments in (21).

(21) a. Ob ètom pro mnogo govorjat

about this - much talk-3.PL

b. pro prosjat ne kurit'

- $\quad$ ask-3.PL not to smoke

c. Ėtu knigu pro pročityvaeš za dva časa

this book - read-2.SG. in two hours

So far, I have only considered present tense contexts. Things are slightly more involved in past tense environments. At first sight, it looks as though there is radical person impoverishment in the past tense; as shown in (22), past tense forms are marked only for gender (which is not marked in the present conjugation) and number.

(22) Past tense conjugation:

čitat' ('read')

\begin{tabular}{|l||l|l|l|}
\hline & MASC & FEM & NEUT \\
\hline \hline $1 . S G$ & čita-1 & čita-l-a & čita-l-o \\
\hline 2.SG & čita-1 & čita-l-a & čita-l-o \\
\hline $3 . S G$ & čita-1 & čita-l-a & čita-l-o \\
\hline
\end{tabular}

\begin{tabular}{|l||l|l|l|}
\hline & MASC & FEM & NEUT \\
\hline \hline 1.PL & čita-l-i & čita-l-i & čita-l-i \\
\hline 2.PL & čita-l-i & čita-l-i & čita-l-i \\
\hline 3.PL & čita-l-i & čita-l-i & čita-l-i \\
\hline
\end{tabular}


Assuming (as I have done so far) that the presence of one impoverishment rule affecting $\mathrm{T}$ (perhaps vacuously) suffices to block pro licensing by $\mathrm{T}$ in general, an impoverishment approach to (22) would be incompatible with the claim that Russian has subject argument pro-drop. What is more, pro-drop can also take place in past tense contexts, even though the forms are not specified for person features at all (see Müller \& Rohrbacher (1989), Růžička (1986)); cf. (23). ${ }^{18}$

(23) Anna postupila verno [CP čto pro rešila [CP stat' vračom ]]
Anna acted correctly that decided-3.SG.PAST to become doctor

As a key to a solution of this problem, a diachronic perspective can be taken: The inflected past tense forms in (23) are historically $l$-participles (with the originally accompanying auxiliaries dropped in modern Russian); as such, they never had any person features in the first place (those features had been located on the auxiliaries). Hence, it seems that the most plausible analysis of these forms is not that an impoverishment rule deletes all person features in past tense contexts, but rather that the inflection markers for past tense are not specified for person features for essentially historical reasons: The markers did not bear person features to begin with; they have been re-analyzed as finite markers in parallel with the disappearance of associated auxiliaries, and they simply have not acquired person features in their new function. This then explains why subject pro-drop is possible in Russian, and in all tenses. ${ }^{19}$ Of course, a lot more would eventually have to be said about pro-drop in Russian, but I will leave it at that, and draw a conclusion. ${ }^{20}$

\section{Conclusion}

The main goal of this paper has been to sketch the outlines of a theory of how morphological properties of verb inflection determine subject argument pro-drop. I have suggested that the notion of morphological richness that is relevant in this context does not rely on counting forms of reference grammar paradigms, but rather involves abstract restrictions on morphological systems that have been independently suggested in Distributed Morphology to capture system-wide patterns of syncretism; viz., impoverishment rules - more specifically, those impoverishment rules that lead to a neutralization of $\phi$-feature distinctions. However, to ensure that morphological impoverishment can have an effect on syntax, it is imperative for this operation to apply pre-syntactically, rather than postsyntactically (as is standardly assumed in Distributed Morphology). Accordingly, I have developed a pre-syntactic approach to morphology that incorporates main features of Distributed Morphology (underspecification, fission, impoverishment), and that I have argued to be independently motivated, given minimalist assumptions. The empirical focus of the study has been on German first; I have then extended the analysis to Icelandic, Modern Irish, and Russian.

\footnotetext{
${ }^{18}$ However, the issue of markedness may arise here again. For instance, in Dobrova's (2002) discussion of acquisition of pronouns by Russian children, it is presupposed that there is an asymmetry between past and present tense as concerns the occurrence of pro-drop in input data.

${ }^{19}$ Note that the analysis here is similar to that which can be given for pro-drop languages like Japanese, Korean, and Chinese in the present approach: Assuming that instances of subject pronoun omission in these languages can indeed involve an empty category pro that undergoes Agree with $\mathrm{T}$ (rather than discourse-governed ellipsis), the generalization in (13) can be met because if there are no $\phi$-features in the first place, there is no motivation for invoking a designated impoverishment rule that deletes $\phi$-features - and it is only the presence of such impoverishment rules that may block pro licensing under present assumptions.

${ }^{20}$ Except for one additional remark: Suppose - counterfactually, assuming the validity of the argument presented above - that Franks (1995) is right in concluding that Russian does not exhibit genuine pro-drop (in any tense), whereas Czech, Polish, and other Slavic languages do. Would it be possible to account for such a situation under present assumptions? The answer is yes: We could stipulate that there is $\phi$-feature neutralizing impoverishment in the past tense in Russian after all; then pro-drop is predicted to be impossible, given (13). The existence of pro-drop in Slavic languages like Czech and Polish could then be traced back to the fact that these languages have retained auxiliary clitics (for 1. and 2. person) with their $l$-participle tenses. Since there would then be no comparable $\phi$-feature impoverishment operation here, T could undergo Agree with pro.
} 
To end this paper, I would like to emphasize that many of the specific results here should be viewed as tentative. The underlying assumption of this paper is that recent advances in theoretical morphology can be put to good use in theoretical syntax, and the main claim is that the abstract notion of impoverishment may offer a better means of measuring morphological richness (as relevant for pro-drop) than is available in more traditional conceptions of morphology. I have presented a specific version of this general approach that makes a number of verifiable predictions; but it seems quite likely that further analysis along these lines will show that significant modifications of the generalization in (13) are necessary.

\section{References}

Abraham, Werner (1991): Null Subjects: From Gothic, Old High German and Middle High German to Modern German, Groninger Arbeiten zur Germanistischen Linguistik 34, 1-28.

Adger, David (2003): Core Syntax. Oxford University Press, Oxford, New York.

Alexiadou, Artemis \& Elena Anagnostopoulou (1998): Parametrizing Agr: Word Order, V-Movement, and EPP-Checking, Natural Language and Linguistic Theory 16, 491-539.

Alexiadou, Artemis \& Gereon Müller (2005): Class Features as Probes. Ms., Universität Stuttgart and Universität Leipzig. To appear in Asaf Bachrach and Andrew Nevins (eds.), Paradigms. Oxford University Press.

Alexiadou, Artemis \& Gisbert Fanselow (2000): On the Correlation between Morphology and Syntax: The Case of V-to-I. In: W. Abraham \& J.-W. Zwart, eds., Proceedings fromthe 15th Comparative Germanic Syntax Workshop. Benjamins, Amsterdam, pp. 219-242.

Aronoff, Mark (1994): Morphology by Itself. MIT Press, Cambridge, Mass.

Avrutin, Sergej \& Bernhard Rohrbacher (1997): Null Subjects in Russian Inverted Constructions. In: Proceedings of the Fourth Annual Workshop on Formal Approaches to Slavic Linguistics. Michigan Slavic Publications, Ann Arbor, pp. 32-53.

Axel, Katrin (2004): Null Subjects and Verb Placement in Old High German. Ms., Universität Tübingen.

Bierwisch, Manfred (1961): Zur Morphologie des deutschen Verbalsystems. PhD thesis, Karl-Marx-Universität Leipzig.

Bierwisch, Manfred (1967): Syntactic Features in Morphology: General Problems of So-Called Pronominal Inflection in German. In: To Honour Roman Jakobson. Mouton, The Hague/Paris, pp. 239-270.

Bobaljik, Jonathan (2002a): Realizing Germanic Inflection: Why Morphology Does Not Drive Syntax, Journal of Comparative Germanic Linguistics 6, 129-167.

Bobaljik, Jonathan (2002b): Syncretism without Paradigms: Remarks on Williams 1981, 1994. In: G. Booij \& J. van Marle, eds., Yearbook of Morphology 2001. Kluwer, Dordrecht, pp. 53-85.

Bonet, Eulália (1991): Morphology after Syntax. PhD thesis, MIT, Cambridge, Mass.

Borer, Hagit (1986): I-Subjects, Linguistic Inquiry 17, 375-416.

Chomsky, Noam (1982): Some Concepts and Consequences of the Theory of Government and Binding. MIT Press, Cambridge, Mass.

Chomsky, Noam (1995): The Minimalist Program. MIT Press, Cambridge, Mass.

Chomsky, Noam (2000): Minimalist Inquiries: The Framework. In: R. Martin, D. Michaels \& J. Uriagereka, eds., Step by Step. MIT Press, Cambridge, Mass., pp. 89-155.

Chomsky, Noam (2001): Derivation by Phase. In: M. Kenstowicz, ed., Ken Hale. A Life in Language. MIT Press, Cambridge, Mass., pp. 1-52.

Chomsky, Noam (2005): On Phases. Ms., MIT, Cambridge, Mass.

Demjjanow, Assinja \& Anatoli Strigin (2000): Case Assignment to Conceptual Structures: The Russian Instrumental. In: M. Kracht \& A. Strigin, eds., Papers on the Interpretation of Case. Vol. 10 of Linguistics in Potsdam, Universität Potsdam, Institut für Linguistik, Potsdam, pp. 75-107.

Dobrova, Galina (2002): "Ontogenetic Universals" and Cross-Linguistic Variations in Children's Acquisition of Personal Pronouns and Kinship Terms. Ms., University of Russia.

Eisenberg, Peter (2000): Grundriß der deutschen Grammatik. Band 1: Das Wort. Metzler, Stuttgart.

Fanselow, Gisbert \& Stefan Frisch (2005): Effects of Processing Difficulty on Judgments of Acceptability. Ms., Universität Potsdam.

Frampton, John (2002): Syncretism, Impoverishment, and the Structure of Person Features. In: M. Andronis, E. Debenport, A. Pycha \& K. Yoshimura, eds., Papers from the Chicago Linguistics Society Meeting. Vol. 38, Chicago, pp. 207-222.

Franks, Steven (1995): Parameters of Slavic Morphosyntax. Oxford University Press, New York and Oxford. 
Gelderen, Elly van (2000): The Role of Person and Position in Old English. In: O. Fischer, A. Rosenbach \& D. Stein, eds., Pathways of Change: Grammaticalization in English. Benjamins, Amsterdam, pp. 187-206. Grewendorf, Günther (1989): Ergativity in German. Foris, Dordrecht.

Grewendorf, Günther (1990): Small pro in German. In: G. Grewendorf \& W. Sternefeld, eds., Scrambling and Barriers. Benjamins, Amsterdam, pp. 295-315.

Grimshaw, Jane (2000): Extended Projection and Locality. In: P. Coopmans, M. Everaert \& J. Grimshaw, eds., Lexical Specification and Insertion. Benjamins, Amsterdam, pp. 115-133.

Grimshaw, Jane \& Vieri Samek-Lodovici (1998): Optimal Subjects and Subject Universals. In: P. Barbosa, D. Fox, P. Hagstrom, M. McGinnis \& D. Pesetsky, eds., Is the Best Good Enough?. MIT Press and MITWPL, Cambridge, Mass., pp. 193-219.

Haider, Hubert (1988): Pro Pro-Drop Drop, Wiener Linguistische Gazette 42/43, 57-79.

Halle, Morris (1997): Distributed Morphology: Impoverishment and Fission. In: B. Bruening, Y. Kang \& M. McGinnis, eds., Papers at the Interface. Vol. 30, MITWPL, pp. 425-449.

Halle, Morris \& Alec Marantz (1993): Distributed Morphology and the Pieces of Inflection. In: K. Hale \& S. J. Keyser, eds., The View from Building 20. MIT Press, Cambridge, Mass., pp. 111-176.

Halle, Morris \& Alec Marantz (1994): Some Key Features of Distributed Morphology. In: A. Carnie, H. Harley \& T. Bures, eds., Papers on Phonology and Morphology. Vol. 21 of MIT Working Papers in Linguistics, MITWPL, Cambridge, Mass., pp. 275-288.

Harley, Heidi \& Rolf Noyer (2003): Distributed Morphology. In: L. Cheng \& R. Sybesma, eds., The Second GLOT International State-of-the-Article Book. Mouton de Gruyter, Berlin, pp. 463-496.

Holmberg, Anders (2004): Null Subjects and Uninterpretable Features: Evidence from Finnish. Ms., University of Durham.

Holmberg, Anders \& Christer Platzack (1995): The Role of Inflection in the Syntax of the Scandinavian Languages. Oxford University Press, Oxford.

Jaeggli, Osvaldo \& Ken Safir (1989): The Null Subject Parameter and Parametric Theory. In: O. Jaeggli \& K. Safir, eds., The Null Subject Parameter. Kluwer, Dordrecht.

Jakobson, Roman (1962): Beitrag zur allgemeinen Kasuslehre. Gesamtbedeutungen der russischen Kasus. In: Selected Writings. Vol. 2, Mouton, The Hague and Paris, pp. 23-71.

Junghanns, Uwe (2005): Bedingungen für die Argumentrealisierung in slavischen Sprachen. Ms., Universität Leipzig.

Kress, Bruno (1982): Isländische Grammatik. 1 edn, VEB Verlag Enzyklopädie, Leipzig.

Legendre, Géraldine, Paul Smolensky \& Colin Wilson (1998): When is Less More? Faithfulness and Minimal Links in Wh-Chains. In: P. Barbosa, D. Fox, P. Hagstrom, M. McGinnis \& D. Pesetsky, eds., Is the Best Good Enough?. MIT Press and MITWPL, Cambridge, Mass., pp. 249-289.

Lumsden, John (1992): Underspecification in Grammatical and Natural Gender, Linguistic Inquiry 23, 469486.

McCloskey, James \& Ken Hale (1984): On the Syntax of Person-Number Inflection in Modern Irish, Natural Language and Linguistic Theory 1, 487-533.

Müller, Gereon (1988): Zur Analyse subjektloser Konstruktionen in der Rektions-Bindungs-Theorie. Thattrace-Effekte und pro-Lizensierung im Russischen. Ms., Universität Frankfurt/Main.

Müller, Gereon (2002): Free Word Order, Morphological Case, and Sympathy Theory. In: G. Fanselow \& C. Féry, eds., Resolving Conflicts in Grammars: Optimality Theory in Syntax, Morphology, and Phonology. Buske, Hamburg, pp. 9-48. Special issue of Linguistische Berichte.

Müller, Gereon (2005a): Subanalyse verbaler Flexionsmarker. Ms., Universität Leipzig.

Müller, Gereon (2005b): Syncretism and Iconicity in Icelandic Noun Declensions: A Distributed Morphology Approach. In: G. Booij \& J. van Marle, eds., Yearbook of Morphology 2004. Springer, Dordrecht, pp. 229271.

Müller, Gereon \& Bernhard Rohrbacher (1989): Eine Geschichte ohne Subjekt. Zur Entwicklung der proTheorie, Linguistische Berichte 119, 3-52.

Noyer, Rolf (1992): Features, Positions, and Affixes in Autonomous Morphological Structure. PhD thesis, MIT, Cambridge, Mass.

Perlmutter, David (1971): Deep and Surface Structure Constraints in Syntax. Holt, Rinehart and Winston, Inc., New York.

Perlmutter, David \& John Moore (2002): Language-Internal Explanation: The Distribution of Russian Impersonals, Language 78, 619-650.

Platzack, Christer (1987): The Scandinavian Languages and the Null Subject Parameter, Natural Language 
and Linguistic Theory 5, 377-402.

Prince, Alan \& Paul Smolensky (2004): Optimality Theory. Constraint Interaction in Generative Grammar. Blackwell. (Original version from 1993).

Richards, Marc (2004): Object Shift and Scrambling in North and West Germanic: A Case Study in Symmetrical Syntax. PhD thesis, University of Cambridge, Cambridge, UK.

Rizzi, Luigi (1986): Null Objects in Italian and the Theory of 'pro', Linguistic Inquiry 17, 501-557.

Roberts, Ian (1993): Verbs and Diachronic Syntax. Kluwer, Dordrecht.

Rohrbacher, Bernhard (1999): Morphology-Driven Syntax: A Theory of V to I Raising and Pro-Drop. Benjamins, Amsterdam.

Rủžička, Rudolf (1986): Funkcionirovanie i Klassifikacija Pustyx Kategorij v Russkom Literaturnom Jazyke, Zeitschrift für Slavistik 31, 388-392.

Stump, Gregory (2001): Inflectional Morphology. Cambridge University Press, Cambridge.

Suñer, Margarita (1983): Pro ${ }_{\text {arb }}$, Linguistic Inquiry 14, 188-191.

Vikner, Sten (1997): V-to-I Movement and Inflection for Person in All Tenses. In: L. Haegeman, ed., The New Comparative Syntax. Longman, London, pp. 189-213.

Vikner, Sten (2001a): V-to-I Movement and Do-Insertion in Optimality Theory. In: G. Legendre, J. Grimshaw \& S. Vikner, eds., Optimality-Theoretic Syntax. MIT Press, Cambridge, Mass., pp. 424-464.

Vikner, Sten (2001b): Verb Movement Variation in Germanic and Optimality Theory. Habilitation thesis, Universität Tübingen.

Wiese, Bernd (1994): Die Personal- und Numerusendungen der deutschen Verbformen. In: K.-M. Köpcke, ed., Funktionale Untersuchungen zur deutschen Nominal- und Verbalmorphologie. Niemeyer, Tübingen, pp. 161-191.

Wiese, Bernd (1999): Unterspezifizierte Paradigmen. Form und Funktion in der pronominalen Deklination, Linguistik Online 4. (www.linguistik-online.de/3_99).

Williams, Edwin (1994): Remarks on Lexical Knowledge, Lingua 92, 7-34.

Wunderlich, Dieter (1996): Minimalist Morphology: The Role of Paradigms. In: G. Booij \& J. van Marle, eds., Yearbook of Morphology 1995. Kluwer, Dordrecht, pp. 93-114.

Wunderlich, Dieter (2004): Is There Any Need for the Concept of Directional Syncretism?. In: G. Müller, L. Gunkel \& G. Zifonun, eds., Explorations in Nominal Inflection. Mouton de Gruyter, Berlin, pp. 373-395. 